\title{
Fuzzy Comprehensive Evaluation on Body Parts' Weight Coefficients towards Sitting Comfort Based on AHP to Limit Entropy Method
}

\author{
Zhenhai Gao $\left(\mathbb{D}\right.$, Mingyue Li $\mathbb{D}^{D}$, Fei Gao $\mathbb{D}$, and Xingyue Wang $(\mathbb{D}$ \\ State Key Laboratory of Automotive Simulation and Control, Jilin University, Changchun 130022, China \\ Correspondence should be addressed to Fei Gao; gaofei123284123@jlu.edu.cn
}

Received 5 March 2019; Revised 15 May 2019; Accepted 20 May 2019; Published 4 June 2019

Academic Editor: Alessandro Naddeo

Copyright (c) 2019 Zhenhai Gao et al. This is an open access article distributed under the Creative Commons Attribution License, which permits unrestricted use, distribution, and reproduction in any medium, provided the original work is properly cited.

In order to quantify the effects of different body parts on sitting comfort, an ontology model for sitting comfort in "human-machine" system was established. In light of the subjectivity and arbitrariness issue of AHP, as well as the characteristic of entropy method be vulnerable to disturbed by extremum, a new weighting method was implemented which corrects subjective data with objective data, named AHP to limit entropy method. An overall comfort formula was created containing shoulder, back, waist, buttock, and thigh. Finally, three other vehicle's seats were tested as comparative verification, with a result showing that the weighted method was effective. And this method can provide an effective approach for evaluating sitting comfort.

\section{Introduction}

As the key index for ergonomic evaluation of vehicle performance, human comfort can accurately measure the influence different body parts have towards sitting comfort, which is very important for seat. Due to physiological property variance in human body, different body part has its unique sensitivity [1], which increases the complexity for evaluating sitting comfort.

Researches on influence of different body parts on sitting comfort, Kamijo et al. [2], by means of correlation analysis between subjective comfort and pressure parameters, the result showed that waist and buttock are the most important body parts to decide the sitting comfort; Schneider [3] carried out experiments about sitting comfort based on a survey of 101 drivers; the results showed that discomfort happened most frequently on waist (26.3\%), then the buttock (14.6\%), and back (9.5\%); Looze et al. [4] reported the relationship between pressure distribution and local discomfort and found that low back and buttock area were closely related to local discomfort; Thakurta et al. [5] studied the relationship between the overall sitting comfort and waist, shoulder, thigh, and buttock, and the results indicated that waist and buttock are more related to the overall sitting comfort, when compared with shoulder and thigh; the research of Noddeo et al. [6] indicated that the comfort level tends to be higher with less pressure in the upper/lower thigh part; Zenk et al. [7] implanted pressure sensor in the middle of the disc intervertebralis; the results showed that, with ideal pressure distribution in intervertebral disc, corresponding sitting posture could achieve higher comfort level; Zejda et al. [8] assessed the symptoms of pain in individual body parts through questionnaire survey; Naddeo, Cappetti, and D'Oria [9] used the photographic data acquisition, the RRP concept. and $\mathrm{NN}$ and defined and built comfort curves for each DOF of human upper limb joints, which is a comfort evaluation method for the upper part of the human body. The research of Kyung [10] and others suggests that the overall sitting comfort is mainly affected by the comfort of upper back and low back; Hartung et al. [11] divided the pressure distribution into certain areas, back, buttock, and thigh and found that the intraindividual variations in the body parts are much smaller than the interindividual variations; Janwantanakul [12] and his team conducted a cross-sectional survey; the 
results showed that the body parts' discomfort proportion among passengers is shoulders (16\%), low back (34\%), upper back (28\%), and wrist (20\%). Liu [13] implemented study about related discomfort ergonomics from dynamic interface chairs, and the results showed that neck, waist, back, and shoulder are the most common body parts to feel discomfort subjectively.

The weighting method this thesis adopts mainly includes the following: (1) subjective weighting method such as delphi method and AHP [14-17] (Analytic Hierarchy Process); (2) objective weighting method like the correlation coefficient method and the entropy method [15, 18, 19]; (3) combination weighting method for example the additive and multiplicative synthesis combination weighting method. Based on improved AHP method, Lu et al. [20] carried out evaluation analysis on sitting comfort with Delphi experiment. Huang et al. [21] applied stimulation on testee's shoulder, back, waist, hip, and thighs, respectively, and measured the relation between different body parts and the overall comfort level with AHP; the influence of each evaluation factors on sitting comfort was measured by questionnaire survey implemented by Unikasari et al. [18], and also they measured the weight coefficients of the factors with AHP and entropy method; Gao [22] calculated the weight of each factor by the combination weighting method, which integrated the subjective weight and objective weight, and finally obtained the synthetic weights of each factor.

Although the above studies have revealed the influence of different body parts on the overall sitting comfort very well, two main problems remained: (1) sitting comfort is an overall feeling of all body parts, researching from only subjective or objective aspect cannot quantify the effects of different body parts on the sitting comfort thoroughly and systematically; (2) a simple average amount of all different body parts' coefficients on the overall sitting comfort cannot quantify the factors' weight coefficients. It cannot provide much guidance and reference for the improvement of sitting comfort.

As for the research methods, there are deficiencies and limits in the subjective/objective/combination weighting methods: (1) subjective weighting method can reflect the will of the testee, but lack objective data; (2) objective weighting method can evaluate the factors weights through objective data [23], but it can be easily disturbed by extremum values, (3) while the traditional combination weighting method tends to ignore the relative importance of the subjective/objective weights. Meanwhile, synthesis combination weighting method is a simple average value of different body parts' weight coefficients on the overall comfort, and the multiplicative synthesis combination weighting method has "multiplier effect". The method relies heavily on the factor relevance and weight result consistency, which is difficult to meet.

To the issues hereinbefore, based on traditional AHP and entropy method, the paper took both testees' subjective feelings and objective data into consideration, presenting a new weighting method-AHP to limit entropy method, which corrects subjective data with objective data. On this basis, testees firstly implemented both subjective/objective tests on

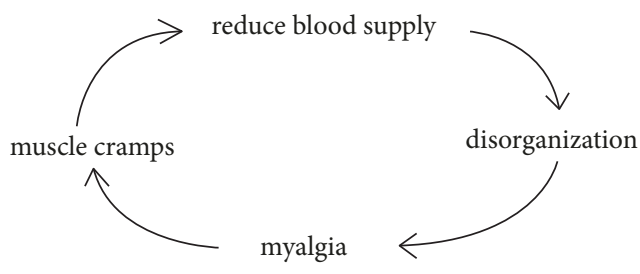

FIGURE 1: Vicious circle of pain.

different body parts influence on overall sitting comfort; secondly, an ontology model of sitting comfort was built, and then calculate the deviation of the expert's opinions about the sitting comfort and filter out the results which meet the standard of the AHP. Thirdly, adjust the subjective data with objective data through AHP to limit entropy method, and measured the body parts' influence on the overall comfort in the sitting posture; at last, three vehicle's seats were tested as comparative verification, and then we evaluated the factors' weights which impact the overall comfort in the sitting posture.

\section{Mechanism of Body Parts' Influence on the Overall Comfort}

The comfort varies between different body parts, which often appears as partly discomfort for drivers and passengers. From physiological anatomy and human biomechanics, driver's torso and head bending forward require a large amount of muscle forces when driving vehicles. In long-distance drive, the muscles are in a contractive condition for long time, which will cause lack of oxygen and potassium and acidic metabolites accumulation in tissues, which will ultimately lead to muscles soreness, even cramps, and lowering the sitting comfort $[24,25]$. The vicious circle of pain shows in Figure 1.

Moreover, the major weight proportion of the head, trunk, and upper limbs transmits downward along spine to ischial tuberosity [26]. From the separation map of driver's torso force Figure 2, we can tell pressure applied to the backrest increases the horizontal force which leads to the ischial tuberosity, causing friction on the skin and subcutaneous tissue, thereby reducing the sitting comfort. There are aorta and nervous system in the back of the thigh, so if it bears pressure too much or too long, the sitting comfort will be reduced.

Based on the above theoretical analysis, the overall comfort is a combination of different body parts' sensation, and there are sensitivity differences between different body parts. In order to improve the local comfort, thereby to improve the overall comfort, the thesis carries out the evaluation and analysis of body parts' weight coefficients towards sitting comfort.

\section{The Establishment of Sitting Comfort Evaluation Model}

Seat is an integrated system composed of several subsystems. Passengers and drivers' sitting comfort is affected by numerous factors $[27,28]$, and the factors contained tend to be 


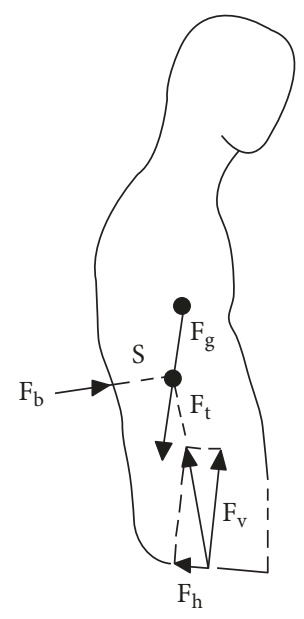

FIGURE 2: The separation map of driver's torso force.

uncertainty, so the sitting comfort is hard to be described by numerical values. It can only be evaluated by qualitative description, such as comfortable and uncomfortable. Based on the human body division from physiological anatomy and body parts which are easy to get uncomfortable while driving, the human body is divided into five regions: shoulder, back, waist, buttock, and thigh. When the testee is sitting on the automobile seat, compute the impact of different body parts on the overall comfort by pairwise comparison with the scale of 1-9 [29]. Apply TEKSCAN pressure measurement system to test the pressure distribution of the shoulder, back, waist, buttock, and thigh. Thereby, put forward a new weighting method, which amends subjective data with objective data, and then evaluate the body parts' weight coefficients towards sitting comfort, as is shown in Figure 3.

\section{The Method to Evaluate Factors' Weights of the Sitting Comfort}

4.1. AHP Method. AHP method is a hierarchical method that presents the qualitative results about subjective judgments in a quantitative term, and the core of AHP is the calculation of factors' weights and the normalization [30-33] to get the weights of each factor. The main steps are as follows:

(1) Establish hierarchical structure. Analyze the characteristics, affiliation, and correlations of factors that affect sitting comfort. Define goal layers, criterion layer, and index layer, and then construct the hierarchical structure.

(2) Construct the pairwise comparison matrix. Pairwise compare factors that affect sitting comfort, and with scale of 1-9 [29] evaluate all the factors. Then create a judgment matrix to calculate the maximum eigenvalue and the eigenvector. After checking the consistency, request the experts to present.

(3) Construct the weight matrix. According to the above analysis, the weight vector which is about $\mathrm{n}$ experts' feelings to $\mathrm{m}$ factors' effect on the sitting comfort is obtained. The weight matrix $\mathrm{W}$ composed by weight vector is as follows:

$$
\mathrm{W}=\left[\begin{array}{ccc}
\mathrm{W}_{11} & \cdots & \mathrm{W}_{1 \mathrm{~m}} \\
\vdots & \cdots & \vdots \\
\mathrm{W}_{\mathrm{n} 1} & \cdots & \mathrm{W}_{\mathrm{nm}}
\end{array}\right]
$$

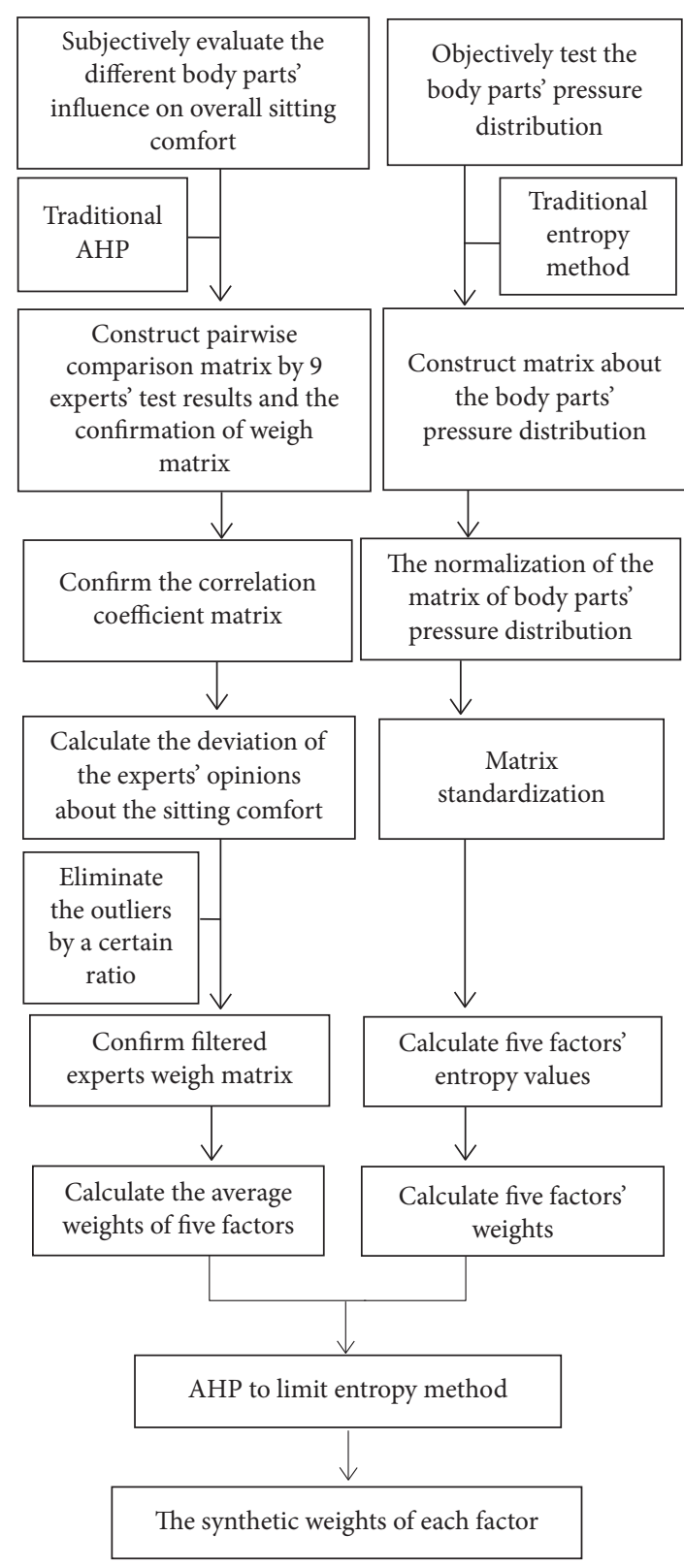

FIGURE 3: The evaluation process of combing subjective and objective weighting methods.

(4) Eliminate the outliers. The correlation coefficient matrix D is constructed, which is about $\mathrm{n}$ experts' feelings to the factors' effect on the sitting comfort.

$$
\begin{aligned}
& d_{i j}=1-\sqrt{\frac{1}{m-1} \sum_{k=1}^{m}\left(W_{i k}-W_{j k}\right)^{2}} \\
& D=\left[\begin{array}{ccc}
d_{11} & \cdots & d_{1 n} \\
\vdots & \cdots & \vdots \\
d_{n 1} & \cdots & d_{n n}
\end{array}\right]
\end{aligned}
$$

in which $D_{i j}=d_{i j}, d_{i i}=1$. 
According to (4), eliminate the weight outliers (from the experts) that deviate the most/more about the sitting comfort test results.

$$
\mathrm{d}_{\mathrm{i}}=\sum_{\mathrm{j}=1}^{\mathrm{n}} \mathrm{d}_{\mathrm{ij}}
$$

In the equation, $\mathrm{d}_{\mathrm{i}}$ indicates the sum of similarity degree of weight based on the results of the i-th expert's opinion and the weights based on the results of the rest experts' opinions about sitting comfort. It is the reflection of the weights deviation of the test result. The smaller the values of $d_{i}$, the higher the deviation, vice versa. Table 1 shows the number of experts and the corresponding portion of elimination.

(5) Calculate the average of weight matrix columns- $W_{j}^{1}$, after screening, and it is the factor's weights.

4.2. Entropy Method. The entropy method, based on the factors' variation degree, is to calculate the factors' objective weights. The higher entropy values, the less information can be obtained from the index data and the lower factors' variation degree will be and then the impact of these factors on the sitting comfort will be slighter [19] and vice versa.

Based on classic entropy method model, the calculation procedures of effects of different factors on the overall comfort are as follows:

(1) Data standardization. Standardize the matrix composed of $h$ arrays and $\mathrm{n}$ factors that affect sitting comfort with

$$
\mathrm{b}_{\mathrm{ij}}=\frac{\mathrm{x}_{\mathrm{ij}}-\mathrm{x}_{\min }}{\mathrm{x}_{\max }-\mathrm{x}_{\min }}
$$

In (5), $x_{\min }$ and $x_{\max }$ represent the most appropriate and inappropriate value of the same factors belong to different evaluation unit, respectively.

(2) Calculate the entropy values of factors. Base on (6), h arrays, and $\mathrm{n}$ factors which affect sitting comfort, the entropy values of factors can be calculated.

$$
E_{j}=-\ln (h)^{-1} \sum_{i=1}^{n} p_{i j} \ln p_{i j}
$$

In (6),

$$
\mathrm{p}_{\mathrm{ij}}=\frac{\mathrm{Y}_{\mathrm{ij}}}{\sum_{\mathrm{i}=1}^{\mathrm{n}} \mathrm{Y}_{\mathrm{ij}}}
$$

(3) Calculate the weights of factors. Bring the above entropy values $E_{j}$ into (8), and then get the factors' weights.

$$
W_{j}=\frac{1-E_{j}}{n-\sum_{j=1}^{n} E_{j}}
$$

4.3. AHP to Limit Entropy Method. Extract the marginal value from the above weights of factors that calculated through AHP. Among them, the minimum value is a, and the maximum value is b. Then use AHP to limit entropy method to revise the weights of factors. The calculation procedures are as follows:
If the weight $\mathrm{W}_{\mathrm{j}}^{2}$ is calculated by entropy method less than the minimum value a, then suppose $W_{j}=a$ and use (9) to reassign the fractional variation of weights.

$$
\begin{aligned}
W_{k}^{s}=\left(W_{j}^{2}-a\right) \frac{W_{k}^{2}}{\sum_{i=j+1}^{n} W_{i}^{2}}+W_{k}^{2} & \\
& \quad(k=j+1, j+2, \ldots, n)
\end{aligned}
$$

If the weight $W_{j}^{2} \in[a, b]$, then suppose $W_{j}=W_{j}^{2}$.

If the weight $W_{j}^{2}>b$, then suppose $W_{j}=b$ and use (10) to redistribute the fractional variation of weights.

$$
\begin{aligned}
W_{k}^{s}=\left(W_{j}^{2}-b\right) \frac{W_{k}^{2}}{\sum_{i=j+1}^{n} W_{i}^{2}}+ & W^{2} \\
& \quad(k=j+1, j+2, \ldots, n)
\end{aligned}
$$

According to above calculation procedure, revise the weights of factors which affect sitting comfort one by one and ultimately obtain the revised weights of the factors. If there are still $\mathrm{W}_{\mathrm{n}}^{\mathrm{s}} \in \notin[\mathrm{a}, \mathrm{b}]$, then use (11) or (12) to redistribute the fractional variation of weights to others, until all the factors' weights meet the requirements.

$$
\begin{aligned}
\mathrm{W}_{\mathrm{k}}^{\mathrm{s}}=\left(\mathrm{W}_{\mathrm{j}}^{2}-\mathrm{a}\right) \frac{\mathrm{W}_{\mathrm{k}}^{2}}{\sum_{\mathrm{i}=1}^{\mathrm{n}} \mathrm{W}_{\mathrm{i}}^{2}-\mathrm{W}_{\mathrm{j}}^{2}}+\mathrm{W}_{\mathrm{k}}^{2} & \\
& (1 \leq \mathrm{k} \leq \mathrm{n}, \mathrm{k} \neq \mathrm{j})
\end{aligned}
$$

or

$$
\begin{aligned}
\mathrm{W}_{\mathrm{k}}^{\mathrm{s}}=\left(\mathrm{W}_{\mathrm{j}}^{2}-\mathrm{b}\right) \frac{\mathrm{W}_{\mathrm{k}}^{2}}{\sum_{\mathrm{i}=1}^{\mathrm{n}} \mathrm{W}_{\mathrm{i}}^{2}-\mathrm{W}_{\mathrm{j}}^{2}}+\mathrm{W}_{\mathrm{k}}^{2} & \\
& (1 \leq \mathrm{k} \leq \mathrm{n}, \mathrm{k} \neq \mathrm{j})
\end{aligned}
$$

\section{The Subjective and Objective Test and Analysis on Sitting Comfort}

5.1. Test Method. The thesis selected 18 experts, as in Table 2, which was based on a sample derived from recruited testees. The testees included four 5th, ten 50th, and four 95th, all with driving experience of more than 3 years and in line with the standards from Human Dimensions of Chinese Adults GB10000-88, so the experiment result can be more typical (the analysis report about the human dimensions of Chinese adults made by China National Institute of Standardization in 2009). Then the subjective and objective tests of the sitting comfort when the testees sitting on the No. 1 seat were performed respectively by using the scale of 1-9 [29] and TEKSCAN pressure measurement system.

Firstly, in the early stage of the test, the testees sat on the seat with a driving posture and drove for about half an hour, in order to eliminate the deviation, caused by the testees' not sitting long enough that the seat deformation is not in line with the real situation. Secondly, the testees kept the driving posture for about 10 minutes, to test the effect of different body parts on the overall comfort, and answered 
TABLE 1: The number of experts and the corresponding portion of elimination.

\begin{tabular}{|c|c|c|c|c|c|c|}
\hline The number of experts & 5 & 6 & 7 & 8 & 9 & 10 \\
\hline The number of eliminated experts by clustering analysis & 1 & $1 \sim 2$ & $1 \sim 2$ & 2 & $2 \sim 3$ & $2 \sim 3$ \\
\hline The number of experts whose results were adopted & 4 & $4 \sim 5$ & $5 \sim 6$ & 6 & $6 \sim 7$ & $7 \sim 8$ \\
\hline
\end{tabular}

every question on the subjective sitting comfort evaluation table. At last, we laid the pressure map flat on the seat surface, and the testees kept driving posture, and then we applied TEKSCAN pressure measurement system to test the pressure distribution between the human body and the seat surface, as is shown in Figure 4.

\subsection{Test Results}

5.2.1. Subjective Test Results. Subjective evaluation employs SAE scale, rating from 1 to 10 . The less the point is, the more the adverse impact corresponding body part has towards sitting comfort, and vice versa. The evaluation includes shoulder, back, waist, buttock, and thigh, and testees obtained the results through questionnaires.

Calculate the factors' weight about No. 1 expert's feelings to the factors' effect on the sitting comfort with AHP. The index layer includes comfort influence of shoulder, back, waist, buttock, and thigh on the overall comfort. According to the above evaluation principle and calculation process about AHP, the pairwise comparison matrix and the weights results of each factors are as in Table 3, with the Consistency Ratio (CR) 0.055 , less than 0.1 , and then the pairwise comparison matrix is totally consistent.

With the same approach, calculate the rest 17 experts' test results and check related Consistency Ratio (CR), and the final results are summarized in Table 4 . Test results present in Table 4 show that the Consistency Ratio (CR) is less than 0.1 and the weights are all in significant difference, while the consistency is in accordance with the requirement.

Based on the subjective test on body parts' effects on the overall sitting comfort, in order to reduce random error of the factors results, eliminate the outliers with (2). Adopt the No. 2 expert, No. 3 expert, No. 4 expert, No. 5 expert, No. 6 expert, No. 7 expert, No. 9 expert, No. 10 expert, No. 11 expert, No. 12 expert, No. 13 expert, No. 14 expert, No. 15 expert, No. 17 expert, and No. 18 expert's opinions about the sitting comfort, based on the corresponding elimination rate and then calculate the average weights, as in Table 5.

5.3. Objective Test Results. Based on the division of human body from anthropotomy, as shown in Figure 5, divide the pressure nephogram into shoulder, back, waist, buttock, and thigh. The different body's mean pressure distribution is summarized in Table 6.

According to the above evaluation principle and calculation process about objective weighting method-entropy method, calculate the weights of factors (as in Table 6) in terms of static comfort in sitting posture. The entropy values and the weights of each factors are shown in Table 7.
5.4. Synthetic Weights. Based on the weights calculated with AHP and entropy method, in order to reduce the deficiency of subjective weighting method that considers only the human experience, while neglecting objective data, to make the results about the factors' effect on the sitting comfort more in line with the reality, hereby, the thesis uses AHP to limit entropy method, correcting the subjective data with objective data, as in Table 8. Furthermore, the method about standard deviation is applied to analyze the similarity of weights determined by three methods, and the results are in Table 9, to enhance the science and rationality of the weights.

From Tables 8 and 9, it is clear that the subjective weights calculated by AHP and the objective weights calculated by entropy method have the smallest similarity, with the amount of 0.820 . The reason different evaluation principles, the subjective weighting method emphasizes personal opinions while the entropy method pays more attention to objective data. The AHP to limit entropy method combined the subjective and objective thoughts together, so it has a high similarity with the weights calculated by AHP and entropy method. Through the above calculation and analysis, the comfort weights of the shoulder, back, waist, buttock, and thigh can be achieved. In a descending order for affecting the overall comfort is the following, the comfort of back (0.348), the comfort of waist (0.310), the comfort of buttock (0.189), the comfort of thigh (0.097), and the comfort of shoulder (0.056).

\section{Verification and Discussion}

In order to test the rationality and applicability of the factors' weights calculated by AHP to limit entropy method, in this thesis, No. 2, No. 3, and No. 4 vehicles' seats were tested as subjective and objective comparative verification, as in Figure 6.

Figure 7 showed the results of the weights of body parts' coefficients on the overall comfort when testees sat on No. 2 vehicle, No. 3 vehicle, and No. 4 vehicle compared with the No. 1 vehicle's test results.

Comparing the test results in Figure 7, when the testees were sitting on No. 2 vehicle, No. 3 vehicle, and No. 4 vehicle, the influence degrees of weights of body parts' coefficients on the overall comfort were consistent with the results of No. 1 vehicle. The factor that has biggest influence on sitting comfort is the comfort of back, the comfort of waist lists second, and the comfort of buttock lists third, while the comforts of thigh and shoulder are relatively smaller. Except the case when testees sat on the No. 2 and No. 3 vehicle, the effects of the comfort of back and waist on the overall sitting comfort slightly differ from the results of No. 1 vehicle, and the difference of weights of body parts' coefficients on the 


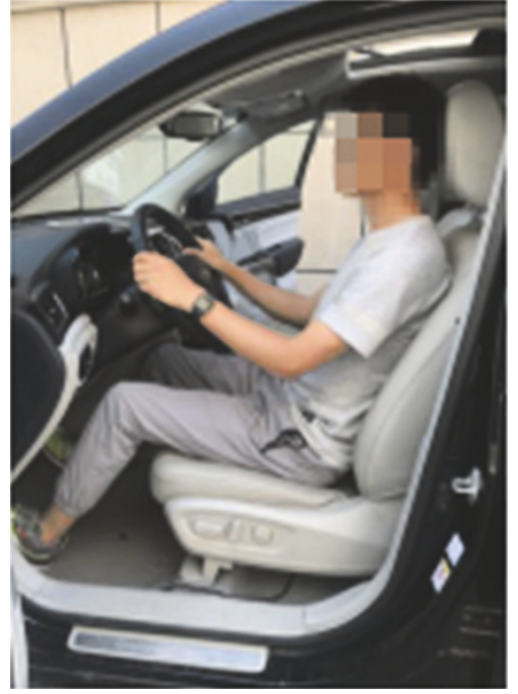

(a)

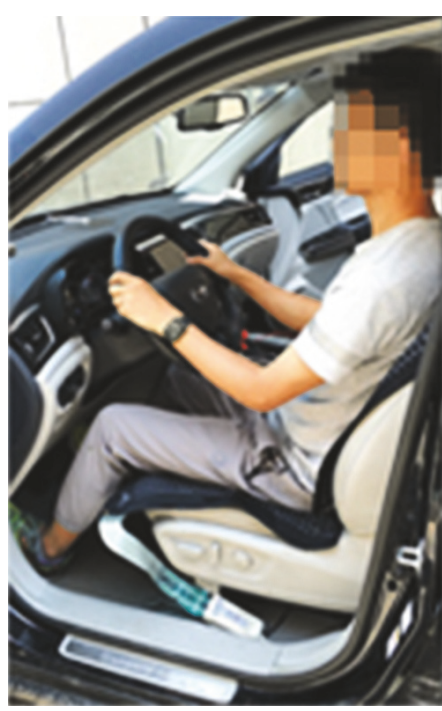

(b)

FIGURE 4: The subjective and objective experiment of No. 1 vehicle. (a) Subjective experiment of No. 1 vehicle. (b) Objective experiment of No. 1 vehicle.

TABLE 2: The basic information about testees.

\begin{tabular}{|c|c|c|c|c|c|c|c|c|c|}
\hline Human parameters & $\begin{array}{c}\text { No. } 1 \\
\text { expert }\end{array}$ & $\begin{array}{c}\text { No. } 2 \\
\text { expert }\end{array}$ & $\begin{array}{c}\text { No. } 3 \\
\text { expert }\end{array}$ & $\begin{array}{c}\text { No. } 4 \\
\text { expert }\end{array}$ & $\begin{array}{c}\text { No. } 5 \\
\text { expert }\end{array}$ & $\begin{array}{l}\text { No. } 6 \\
\text { expert }\end{array}$ & $\begin{array}{l}\text { No. } 7 \\
\text { expert }\end{array}$ & $\begin{array}{c}\text { No. } 8 \\
\text { expert }\end{array}$ & $\begin{array}{l}\text { No. } 9 \\
\text { expert }\end{array}$ \\
\hline Height $(\mathrm{cm})$ & 156 & 155 & 154 & 155 & 169 & 174 & 173 & 174 & 170 \\
\hline Weight $(\mathrm{kg})$ & 52 & 48 & 50 & 51 & 64 & 60 & 62 & 65 & 65 \\
\hline Driving experience (year) & 6 & 17 & 6 & 3 & 9 & 8 & 10 & 3 & 3 \\
\hline Human parameters & $\begin{array}{l}\text { No.10 } \\
\text { expert }\end{array}$ & $\begin{array}{c}\text { No.11 } \\
\text { expert }\end{array}$ & $\begin{array}{c}\text { No.12 } \\
\text { expert }\end{array}$ & $\begin{array}{l}\text { No.13 } \\
\text { expert }\end{array}$ & $\begin{array}{c}\text { No.14 } \\
\text { expert }\end{array}$ & $\begin{array}{l}\text { No.15 } \\
\text { expert }\end{array}$ & $\begin{array}{l}\text { No.16 } \\
\text { expert }\end{array}$ & $\begin{array}{l}\text { No.17 } \\
\text { expert }\end{array}$ & $\begin{array}{c}\text { No.18 } \\
\text { expert }\end{array}$ \\
\hline Height $(\mathrm{cm})$ & 171 & 173 & 172 & 174 & 170 & 188 & 182 & 186 & 183 \\
\hline Weight $(\mathrm{kg})$ & 64 & 61 & 61 & 64 & 66 & 72 & 69 & 72 & 70 \\
\hline Driving experience (year) & 6 & 6 & 11 & 4 & 3 & 4 & 9 & 4 & 7 \\
\hline
\end{tabular}

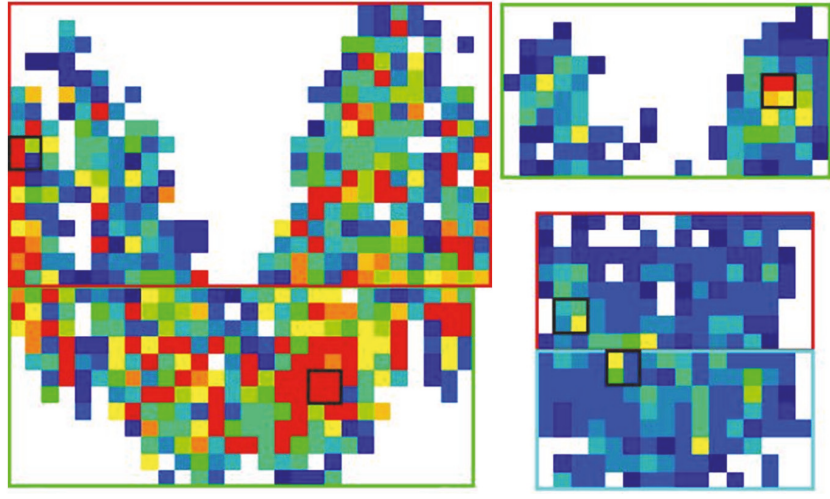

FIgURE 5: The regional division of factors in term of static comfort in sitting posture.

overall comfort tested by the three other vehicles is less than $5 \%$. It demonstrates that the results of factors' weights have a relatively strong consistency, which means the weighting method has broad applicability. Furthermore, different seat structure has less effect on distribution of the weights of body parts.

Sum and average the weights of body parts' coefficients on the overall sitting comfort of the four vehicles' experiment results, the comfort index can be achieved. The comfort of shoulder $B_{1}$, the comfort of back $B_{2}$, the comfort of waist $B_{3}$, the comfort of buttock $B_{4}$, and the comfort of thigh $B_{5}$. Suppose the overall sitting comfort is $\mathrm{Y}_{1}$, then $\mathrm{Y}_{1}=0.056 \mathrm{~B}_{1}+$ $0.346 \mathrm{~B}_{2}+0.308 \mathrm{~B}_{3}+0.193 \mathrm{~B}_{4}+0.096 \mathrm{~B}_{5}$.

Through the above analysis, it is clear that compared with the comfort of thigh and shoulder, the comforts of back, waist, and buttock have a greater impact on the overall sitting comfort. And then to drivers, the back is the most sensitive part of human body, while the waist and buttock list second. Therefore, in the future seat design, we should ensure the comfort of the above body parts.

In light of above test, it is demonstrated that the results are corresponding to the human biomechanics. In the sitting position, about $80 \%$ of body mass is transmitted downward to the seat surface, through spine, sacrum, intervertebral 
TABLE 3: The matrix and weights of factors in term of static comfort in sitting posture.

\begin{tabular}{lcccccc}
\hline $\mathrm{B}$ & $\mathrm{B}_{1}$ & $\mathrm{~B}_{2}$ & $\mathrm{~B}_{3}$ & $\mathrm{~B}_{4}$ & $\mathrm{~B}_{5}$ & Weight \\
\hline $\mathrm{B}_{1}$ & 1 & 2 & $1 / 2$ & $1 / 3$ & 1 & 0.137 \\
$\mathrm{~B}_{2}$ & $1 / 2$ & 1 & $1 / 3$ & $1 / 2$ & $1 / 2$ & 0.078 \\
$\mathrm{~B}_{3}$ & 2 & 3 & 4 & $1 / 4$ & $1 / 2$ & 0.169 \\
$\mathrm{~B}_{4}$ & 3 & 4 & 2 & $1 / 3$ & 1 & 0.441 \\
$\mathrm{~B}_{5}$ & 1 & 2 & & & 0.175 \\
\hline
\end{tabular}

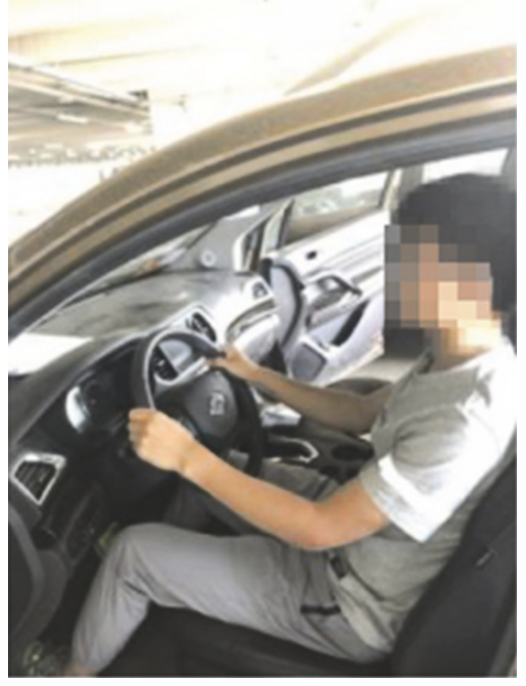

(a)

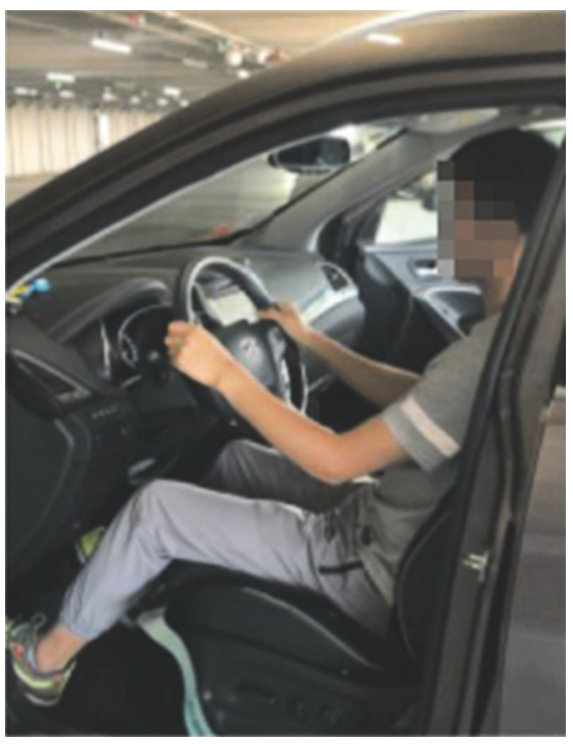

(d)

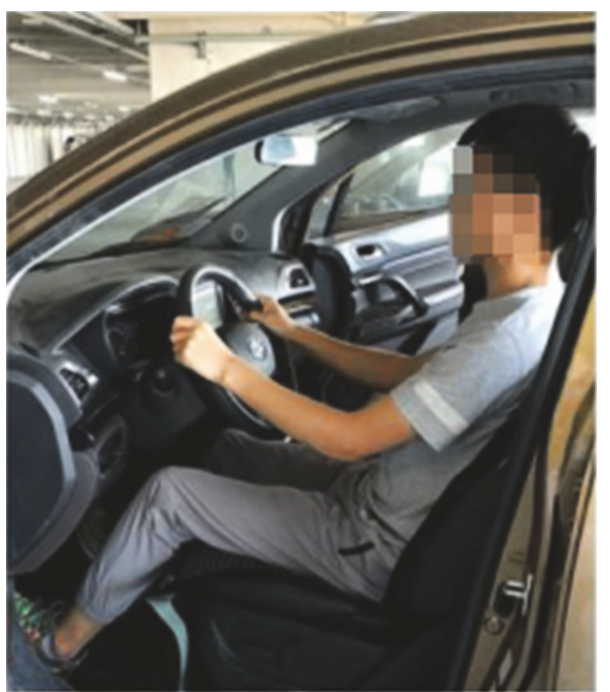

(b)

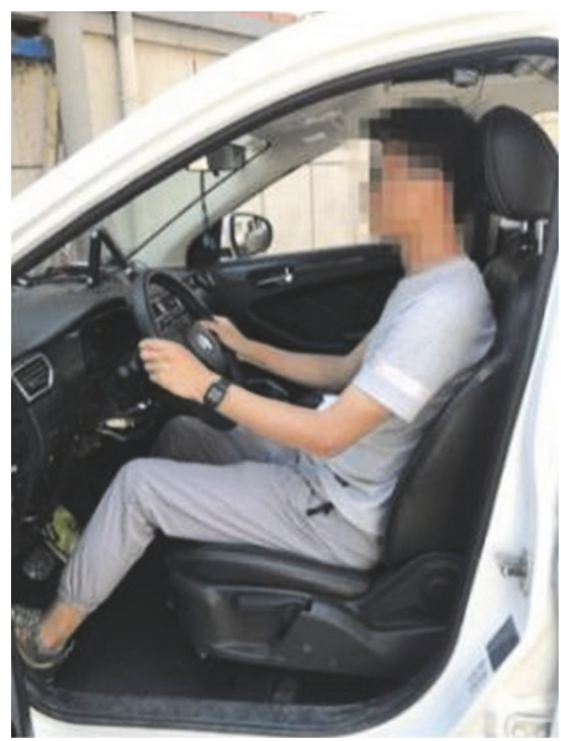

(e)

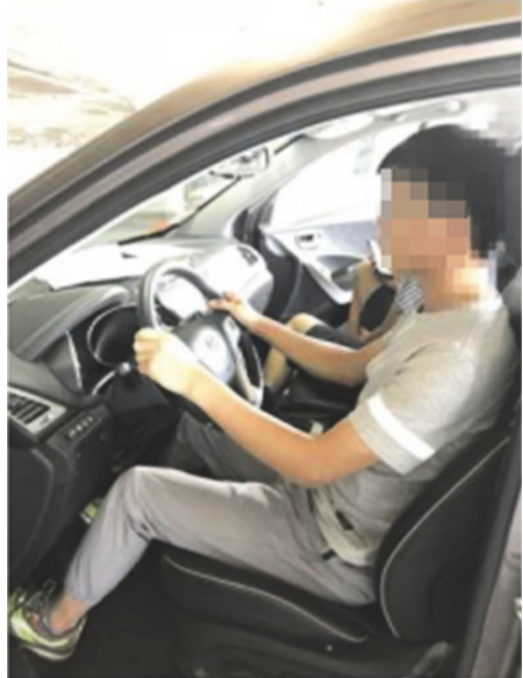

(c)

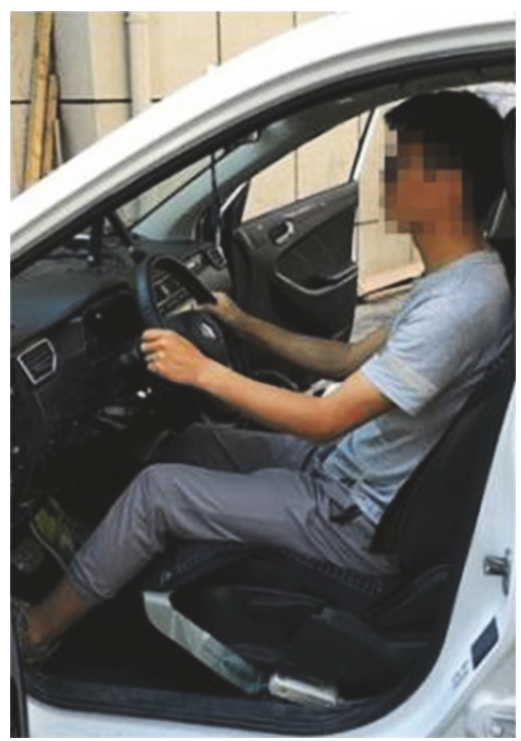

(f)

Figure 6: The map of three vehicle seats' subjective and objective experiments. (a) Subjective experiment of No. 2 vehicle. (b) Objective experiment of No. 2 vehicle. (c) Subjective experiment of No. 3 vehicle. (d) Objective experiment of No. 3 vehicle. (e) Subjective experiment of No. 4 vehicle. (f) Objective experiment of No. 4 vehicle.

disc, and soft tissue, and then the comfort of buttock has a relatively higher effect on the overall sitting comfort. The main structure of the waist and back is spine, and its stability is maintained by the muscles and ligaments that surround the intervertebral disc and spine. It is of very complex structure and linked to other body parts, which means it has a greater influence on the overall sitting comfort. Besides, the vertebral body bears very high pressure from upper torso. And the pressure tends to get higher from top to the coccygeal, so the comforts of back and waist have direct impact on the 


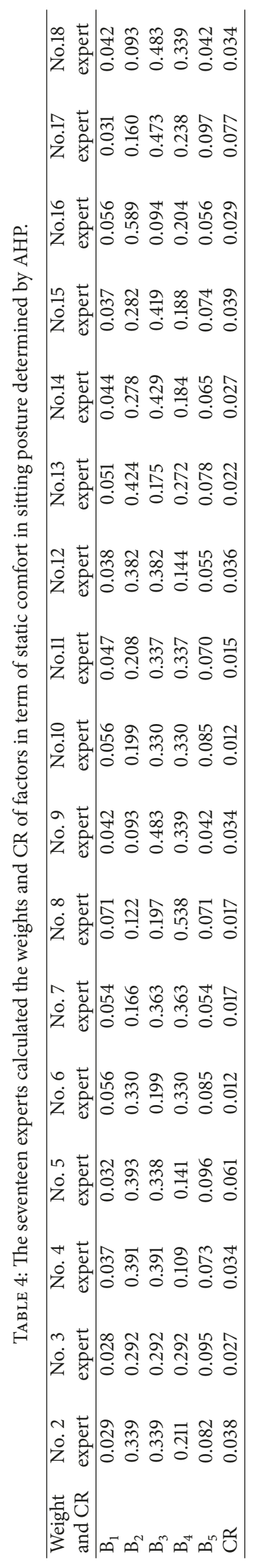


TABLE 5: The average weights of factors in term of static comfort in sitting posture determined by AHP

\begin{tabular}{lr}
\hline $\mathrm{B}$ & Average weight \\
\hline $\mathrm{B}_{1}$ & 0.042 \\
$\mathrm{~B}_{2}$ & 0.269 \\
$\mathrm{~B}_{3}$ & 0.362 \\
$\mathrm{~B}_{4}$ & 0.255 \\
$\mathrm{~B}_{5}$ & 0.073 \\
\hline
\end{tabular}

TABLE 6: The objective values of Pmean of factors in term of static comfort in sitting posture.

\begin{tabular}{|c|c|c|c|c|c|}
\hline Expert & Shoulder & Back & Waist & Buttock & Thigh \\
\hline No. 15th & 0.34 & 0.58 & 0.41 & 1.07 & 0.68 \\
\hline No. 25 th & 0.37 & 0.49 & 0.63 & 1.09 & 0.65 \\
\hline No. 3 th & 0.38 & 0.59 & 0.4 & 1.06 & 0.62 \\
\hline No. 4 th & 0.38 & 0.5 & 0.61 & 1.1 & 0.66 \\
\hline No. 150 th & 0.51 & 0.46 & 0.53 & 1.08 & 0.91 \\
\hline No. 250 th & 0.57 & 0.52 & 0.72 & 1.09 & 0.78 \\
\hline No. 350 th & 0.43 & 0.5 & 0.52 & 1.21 & 0.59 \\
\hline No. 4 50th & 0.52 & 0.41 & 0.47 & 1 & 0.82 \\
\hline No. 5 50th & 0.36 & 0.63 & 0.56 & 0.83 & 1.09 \\
\hline No. 6 50th & 0.51 & 0.48 & 0.53 & 1.1 & 0.83 \\
\hline No. 7 50th & 0.65 & 0.51 & 0.75 & 1.11 & 0.79 \\
\hline No. 8 50th & 0.4 & 0.49 & 0.5 & 1.2 & 0.6 \\
\hline No. 950 th & 0.54 & 0.42 & 0.46 & 1.01 & 0.79 \\
\hline No. 10 50th & 0.38 & 0.65 & 0.57 & 1.06 & 0.82 \\
\hline No. 195 th & 0.41 & 0.45 & 0.76 & 1.2 & 0.66 \\
\hline No. 2 95th & 0.46 & 0.64 & 0.62 & 1.22 & 0.73 \\
\hline No. 3 95th & 0.36 & 0.49 & 0.78 & 1.18 & 0.61 \\
\hline No. 4 95th & 0.44 & 0.63 & 0.71 & 1.13 & 0.7 \\
\hline
\end{tabular}

TABLE 7: The entropy values and entropy weights of factors in term of static comfort in sitting posture.

\begin{tabular}{lcc}
\hline $\mathrm{B}$ & Entropy value & Weight \\
\hline $\mathrm{B}_{1}$ & 0.885 & 0.245 \\
$\mathrm{~B}_{2}$ & 0.904 & 0.206 \\
$\mathrm{~B}_{3}$ & 0.914 & 0.184 \\
$\mathrm{~B}_{4}$ & 0.948 & 0.112 \\
$\mathrm{~B}_{5}$ & 0.882 & 0.253 \\
\hline
\end{tabular}

TABLE 8: The weights determined by comprehensive methods.

\begin{tabular}{lc}
\hline $\mathrm{B}$ & AHP to limit entropy method \\
\hline $\mathrm{B}_{1}$ & 0.056 \\
$\mathrm{~B}_{2}$ & 0.348 \\
$\mathrm{~B}_{3}$ & 0.310 \\
$\mathrm{~B}_{4}$ & 0.189 \\
$\mathrm{~B}_{5}$ & 0.097 \\
\hline
\end{tabular}

overall sitting comfort. As the joints between the limbs and the trunk, shoulders and thighs have larger motion range and are more nimble than other body parts since they do not have much constraining force. Drivers can reduce the discomfort of the shoulders and thighs by moving in a certain range, and the discomfort effects on the overall comfort caused by the shoulder and thigh can be reduced.

\section{Conclusion}

Based on the AHP and entropy method, considering the deficiencies and limitations of the subjective and objective weighting method, the thesis put forward a new weighting method which corrects subjective data with objective data. With three other vehicle's seats tested as comparative verification, the main conclusions are as follows:

(1) Through the subjective and objective tests about sitting comfort, we established the ontology model for sitting comfort in a "human-machine" system and calculated the weights of the factors which are about experts' feelings to the 
TABLE 9: The similarity of the weights determined by three methods.

\begin{tabular}{lccc}
\hline The weighting method & AHP & Entropy method & AHP to limit entropy method \\
\hline AHP & 1 & 0.820 & 0.941 \\
Entropy method & 0.820 & 1 & 0.974 \\
AHP to limit entropy method & 0.941 & 0.974 & 1 \\
\hline
\end{tabular}
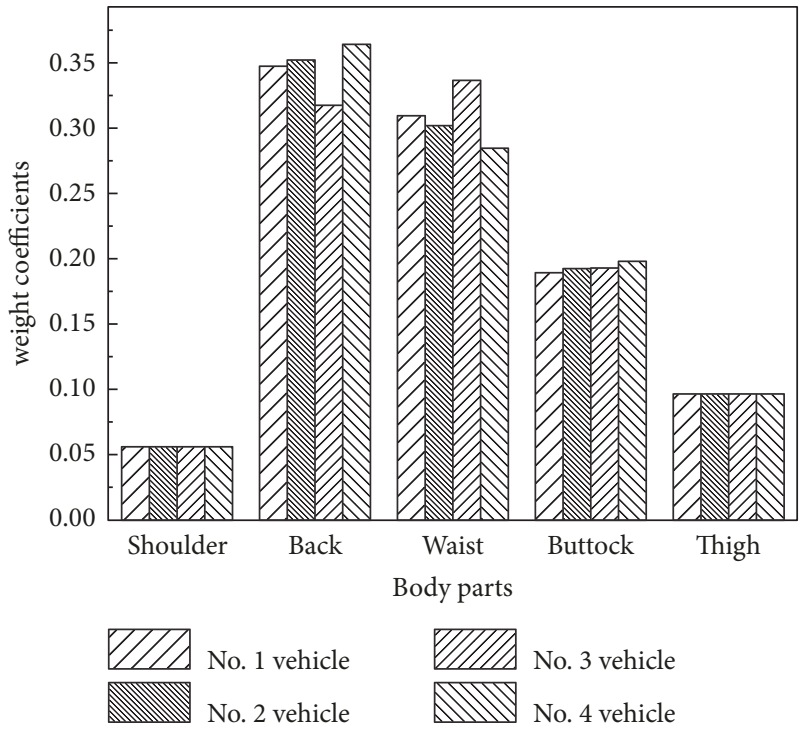

FIGURE 7: The weights of body parts' coefficients on the overall sitting comfort of the four vehicles' experiment results.

factors' effect on the sitting comfort calculated by AHP and entropy method.

(2) A new weighting method which corrects subjective data with objective data was put forward, and finally we obtained the weights of the comfort of shoulder $B_{1}$, the comfort of back $B_{2}$, the comfort of waist $B_{3}$, the comfort of buttock $\mathrm{B}_{4}$, and the comfort of thigh $\mathrm{B}_{5}$ on the overall sitting comfort are $0.056,0.346,0.308,0.193$, and 0.096 , respectively.

(3) By comparing the results with the comparative verification results, the efficiency and reliability of this weighting method were proved, and the seat structure has little influence on the weights of different body parts' effect on the overall sitting comfort.

The above conclusion offers vehicle seat design reference about different body parts' influence on the sitting comfort. In the follow-up study, we will bring in more objective data such as EMG and EEG, etc., for further improvement of the evaluation system of the sitting comfort.

\section{Data Availability}

The data used to support the findings of this study are available from the corresponding author upon request.

\section{Conflicts of Interest}

The authors declare that they have no conflicts of interest.

\section{Acknowledgments}

This work presented in this paper is supported by the National Natural Science Foundation of China (Grant No. 51775236), National Natural Science Foundation of China (Grant No. U1564214), and the National Key Research and Development Program of China (No. 2017YFB0102600).

\section{References}

[1] A. Naddeo, M. Apicella, and D. Galluzzi, "Comfort-driven design of car interiors: a method to trace Iso-comfort surfaces for positioning the dashboard commands," SAE Technical Papers, vol. 2015, 2015.

[2] K. Kamijo, H. Tsujimura, H. Obara, and M. Katsumata, "Evaluation of seating comfort," SAE Technical Papers, 1982.

[3] L. W. Schneider, "Survey of driver seating discomfort and related factors," IEEE Network, vol. 5, no. 6, pp. 2-8, 1989.

[4] M. P. de Looze, L. F. M. Kuijt-Evers, and J. van Dieën, "Sitting comfort and discomfort and the relationships with objective measures," Ergonomics, vol. 46, no. 10, pp. 985-997, 2003.

[5] K. Thakurta, D. Koester, N. Bush, and S. Bachle, "Evaluating short and long term seating comfort," SAE Technical Papers, 1995.

[6] A. Naddeo, R. Califano, and P. Vink, "The effect of posture, pressure and load distribution on (dis)comfort perceived by students seated on school chairs," International Journal on Interactive Design and Manufacturing, vol. 12, no. 4, pp. 11791188, 2018.

[7] R. Zenk, M. Franz, H. Bubb, and P. Vink, "Technical note: spine loading in automotive seating," Applied Ergonomics, vol. 43, no. 2, pp. 290-295, 2012.

[8] J. E. Zejda, J. Bugajska, M. Kowalska et al., "Upper extremities, neck and back symptoms in office employees working at computer stations," Medycyna Pracy, vol. 60, no. 5, pp. 359-367, 2009.

[9] A. Naddeo, N. Cappetti, and C. D’Oria, "Proposal of a new quantitative method for postural comfort evaluation," International Journal of Industrial Ergonomics, vol. 48, pp. 25-35, 2015.

[10] G. Kyung and M. A. Nussbaum, "Driver sitting comfort and discomfort (part II): Relationships with and prediction from interface pressure," International Journal of Industrial Ergonomics, vol. 38, no. 5-6, pp. 526-538, 2008.

[11] J. Hartung, C. Mergl, and H. Bubb, "Reliability of pressure measurement on car seats," SAE Technical Papers, vol. 113, pp. 874-880, 2004.

[12] P. Janwantanakul, P. Pensri, V. Jiamjarasrangsri, and T. Sinsongsook, "Prevalence of self-reported musculoskeletal symptoms among office workers," Occupational Medicine, vol. 58, no. 6, pp. 436-438, 2008.

[13] Z. Liu, Ergonomic Studies of Reducing Sitting Discomfort by Dynamic Interface Chairs, Hang Zhou, Zhe Jiang University, 2011. 
[14] S. Nikou and J. Mezei, "Evaluation of mobile services and substantial adoption factors with Analytic Hierarchy Process (AHP)," Telecommunications Policy, vol. 37, no. 10, pp. 915-929, 2013.

[15] H. Fazlollahtabar, "A subjective framework for seat comfort based on a heuristic multi criteria decision making technique and anthropometry," Applied Ergonomics, vol. 42, no. 1, pp. 16$28,2010$.

[16] T. L. Saaty, The Analytic Hierarchy Process, vol. 5, Mc Graw Hill, New York, NY, USA, 1980.

[17] G. Oliva, R. Setola, and A. Scala, "Sparse and distributed analytic hierarchy process," Automatica, vol. 85, pp. 211-220, 2017.

[18] F. Unikasari, I. Iftadi, W. Jauhari, and D. Danardono, "Study of the factors that affecting automobile seat comfort," in Proceedings of the 2013 Joint International Conference on Rural Information \& Communication Technology and Electric-Vehicle Technology (rICT \& ICeV-T), pp. 1-4, Bandung, Indonesia, November 2013.

[19] D. N. Ilham and S. Mulyana, "Sistem pendukung keputusan pemilihan subkontrak menggunakan metode entropy dan TOPSIS," IJCCS (Indonesian Journal of Computing and Cybernetics Systems), vol. 5, no. 2, pp. 12-19, 2011.

[20] Z. Lu, S. Li, S. Felix, J. Zhou, and B. Cheng, "Driving comfort evaluation of passenger vehicles with natural language processing and improved AHP," Qinghua Daxue Xuebao/Journal of Tsinghua University, vol. 56, no. 2, pp. 137-143, 2016.

[21] S. Huang, Z. Zhang, Q. Yuan, Z. Xu, and Y. He, "Weight coefficients of different body parts to whole bodyin terms of static comfort in sitting posture," Qiche Gongcheng/Automotive Engineering, vol. 38, no. 7, pp. 889-895, 2016.

[22] F. Gao, Study of Driver'S Fatigue Mechanism and Driving Comfort Evaluation Based on Musculoskeletal Biomechanics, Jilin University, Jilin, China, 2017.

[23] M. Ivanco, G. Hou, and J. Michaeli, "Sensitivity analysis method to address user disparities in the analytic hierarchy process," Expert Systems with Applications, vol. 90, pp. 111-126, 2017.

[24] R. H. M. Goossens, R. Zegers, G. A. H. van Dijke, and C. J. Snijders, "Influence of shear on skin oxygen tension," Clinical Physiology, vol. 14, no. 1, pp. 111-118, 1994.

[25] A. Akgunduz, S. Rakheja, and A. Tarczay, "Distributed occupant-seat interactions as an objective measure of seating comfort," International Journal of Vehicle Design, vol. 65, no. 4, pp. 293-313, 2014.

[26] Z. Gao, F. Gao, C. Shen, and Y. Cheng, "Analyses of driver sitting comfort in different automotive seat-pan angle," Journal of Hunan University Natural Sciences, vol. 44, no. 8, pp. 43-49, 2017.

[27] I. Kamp, "The influence of car-seat design on its character experience," Applied Ergonomics, vol. 43, no. 2, pp. 329-335, 2012.

[28] N. Alessandro and M. Sandro, "Postural comfort inside a car: Development of an innovative model to evaluate the discomfort level," SAE International Journal of Passenger Cars-Mechanical Systems, vol. 2, no. 1, pp. 1065-1070, 2009.

[29] T. L. Saaty, "The analytic hierarchy process," in Proceedings of the Second International Seminar on Operational Research in the Basque Provinces, vol. 4, pp. 189-234, 1996.

[30] X. W. Fu, The research and application of fuzzy AHP, Harbin Institute of Technology, Harbin, China, 2011.
[31] J. Bao, J. Zhang, F. Li, C. Liu, and S. Shi, "Social benefits of the mine occupational health and safety management systems of mines in China and Sweden based on a fuzzy analytic hierarchy process: a comparative study," Journal of Intelligent \& Fuzzy Systems: Applications in Engineering and Technology, vol. 31, no. 6, pp. 3113-3120, 2016.

[32] J. Zhang, X. Chen, and Q. Sun, "An assessment model of safety production management based on fuzzy comprehensive evaluation method and behavior-based safety," Mathematical Problems in Engineering, vol. 2019, Article ID 4137035, 11 pages, 2019.

[33] W. Wang, S. Yu, S. Wang et al., "Multilevel comprehensive evaluation and decision making of ergonomics," Mathematical Problems in Engineering, vol. 2015, Article ID 689203, 9 pages, 2015. 


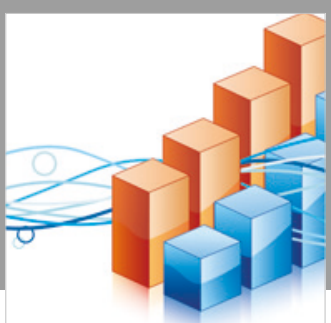

Advances in

Operations Research

\section{-n-m}
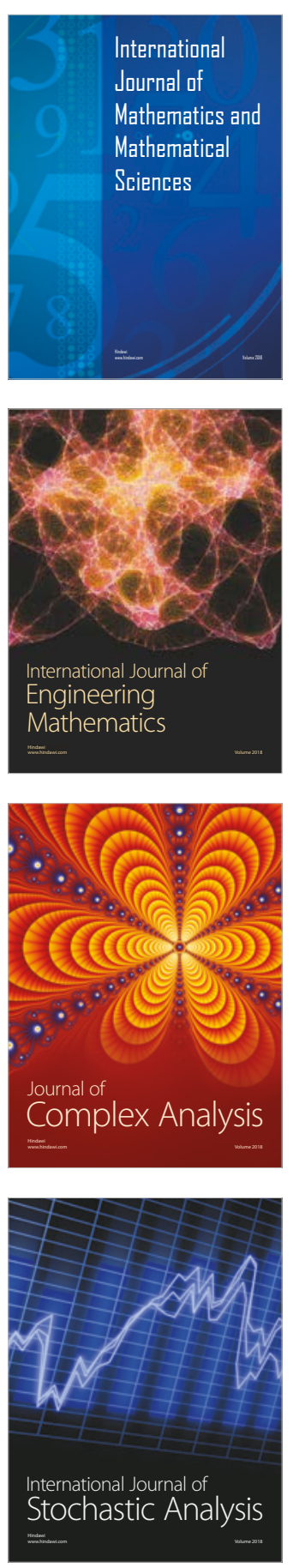
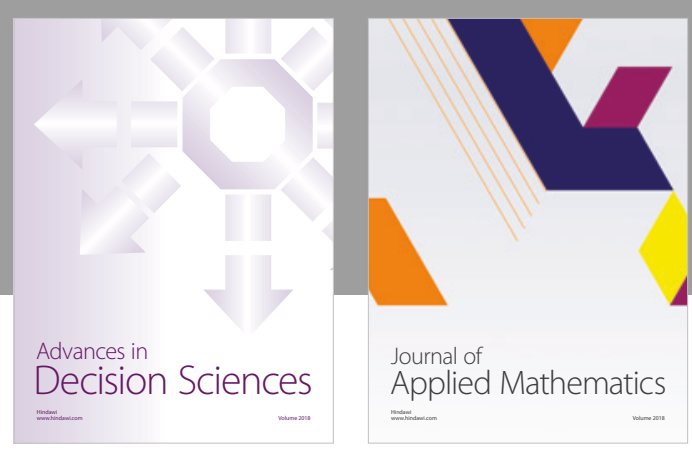

Journal of

Applied Mathematics
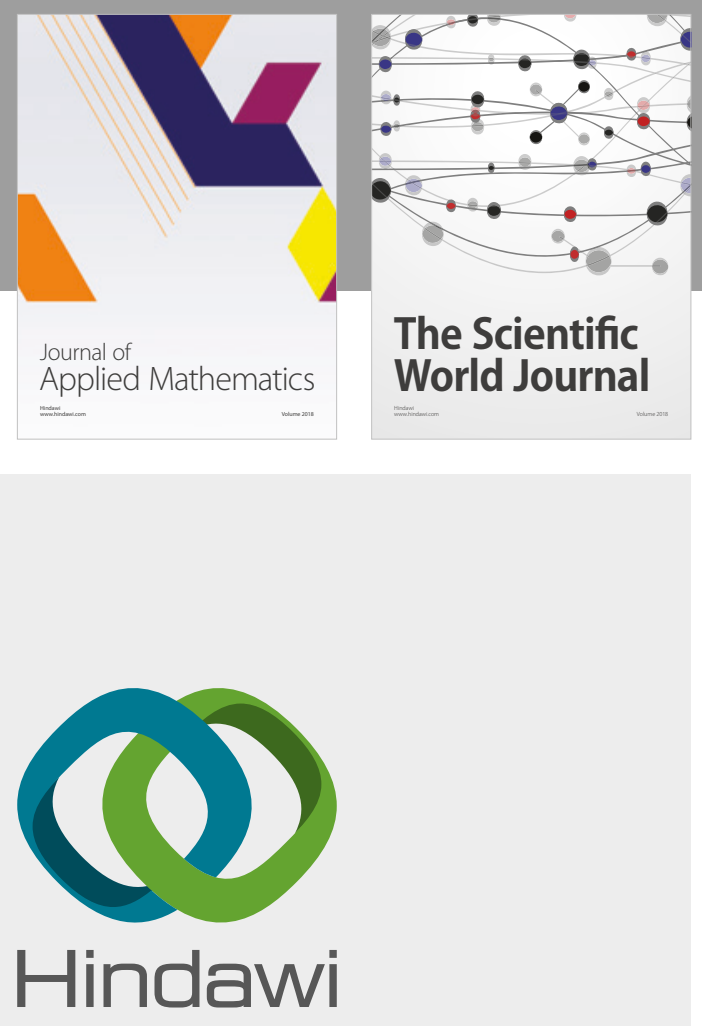

Submit your manuscripts at

www.hindawi.com

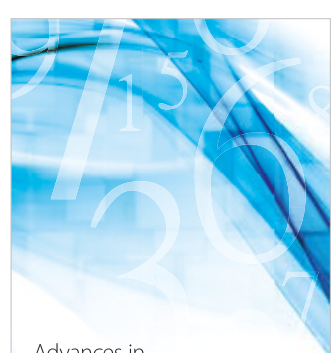

Advances in
Numerical Analysis
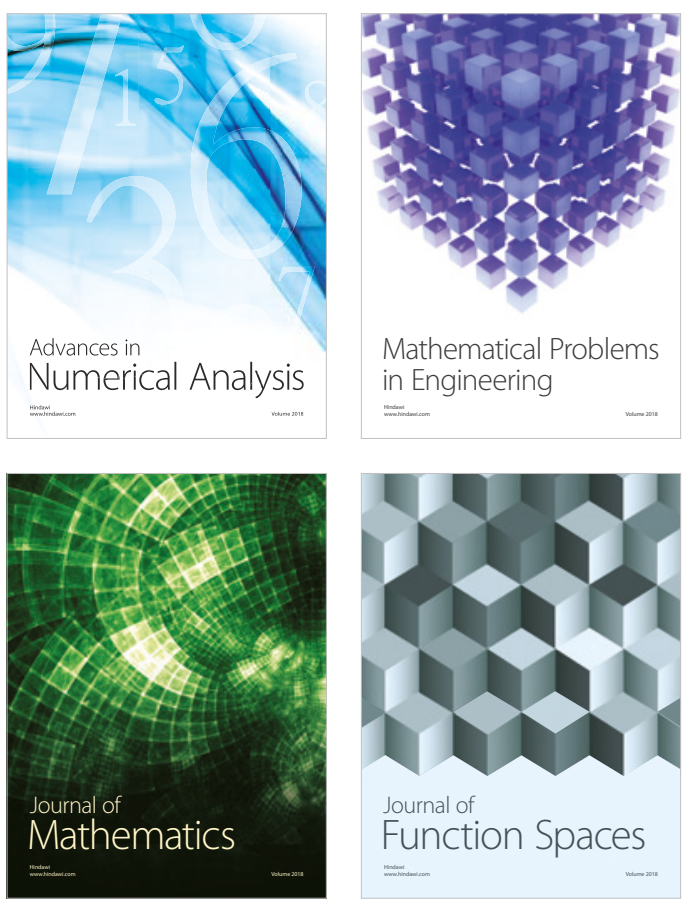

Mathematical Problems in Engineering

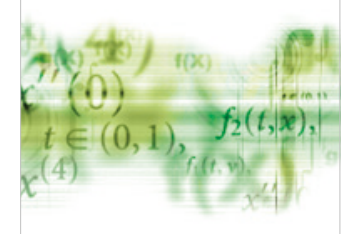

International Journal of

Differential Equations

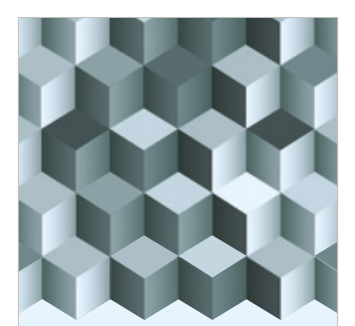

Journal of

Function Spaces

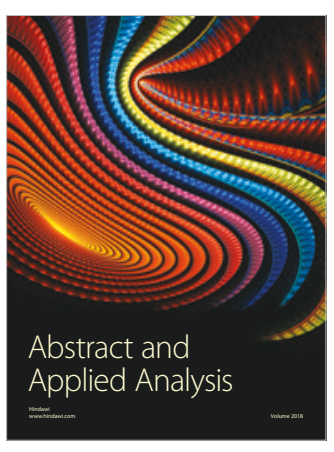

The Scientific

World Journal

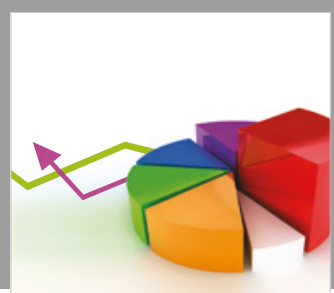

Journal of

Probability and Statistics
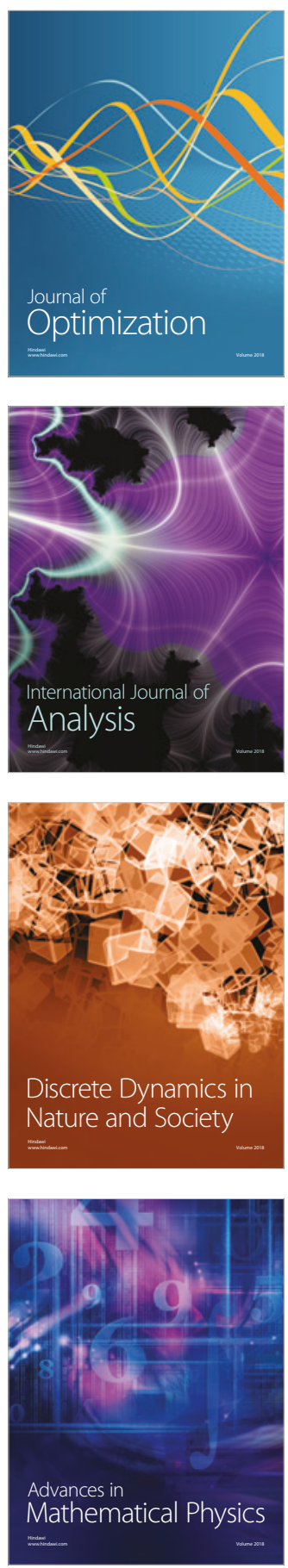